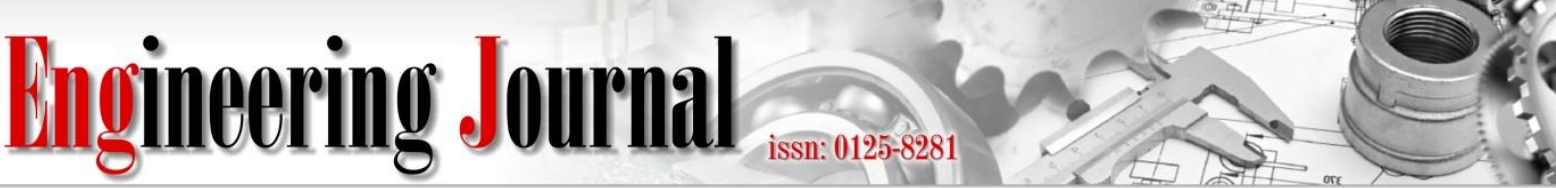

Article

\section{Analyzing Productivity and Behavior of Plastic Drop- Off Points: A Case Study of Send Plastic Home Project in Plastic Waste Recycling during COVID-19 Outbreak}

\author{
Pavinee Pongpunpurt ${ }^{1, a}$, Natsuda Navamajiti ${ }^{2}$, Kerkritt Sriroongvikrai ${ }^{3}$, \\ Muentawan Onnom ${ }^{1}$, Pat Pinitjitsamut ${ }^{1}$, Pisut Painmanakul ${ }^{1,4,5}$, \\ Nattawin Chawaloesphonsiya ${ }^{2,4,5}$, and Thaksina Poyai ${ }^{1,,{ }^{*}}$ \\ 1 Department of Environmental Engineering, Faculty of Engineering, Chulalongkorn University, Bangkok \\ 10330, Thailand \\ 2 Faculty of Engineering, Chulalongkorn University, Bangkok 10330, Thailand \\ 3 Department of Civil Engineering, Faculty of Engineering, Chulalongkorn University, Bangkok 10330, \\ Thailand \\ 4 Research Unit on Technology for Oil Spill and Contamination Management, Chulalongkorn University, \\ Bangkok 10330, Thailand \\ 5 Research Program on Development of Technology and Management Guideline for Green Community, \\ Center of Excellence on Hazardous Substance Management (HSM), Bangkok 10330, Thailand \\ E-mail: apavinee.kimchi@gmail.com, b, ${ }^{*}$ mookthaksina@gmail.com (Corresponding author)
}

\begin{abstract}
In this work, the Productivity Index (PI) was developed for evaluating ten plastic drop-off points along the Sukhumvit Road, Bangkok, Thailand. Factor Analysis of Mixed Data (FAMD) was employed to study the effects of various parameters on drop-off point's performance. To explore plastic separation behaviors, the structured questionnaires were created based on the extended Theory of Planned Behavior, and the questionnaire's responses were then analyzed through the Structural Equation Model (SEM). The highest PI (0.0058) was observed from a drop-off point located in the shopping mall while that installed in a restaurant exhibited the lowest PI (0.0008). Besides environmental attitude and perceived behavioral control, a drop-off point facility was proved as another factor influencing people's intention towards plastic waste separation behavior. To improve the PI, drop-off point's bin design and location should be carefully optimized. Moreover, public relation on drop-off point campaigns and knowledge on household plastic waste separation should be promoted. These findings are helpful for the improvement or expansion of plastic dropoff point facilities as well as for the future development of waste recycling policy.
\end{abstract}

Keywords: Drop-off points, productivity index, extended theory of planned behavior (TPB), factor analysis of mixed data (FAMD), plastic waste separation.

ENGINEERING JOURNAL Volume 25 Issue 10

Received 22 February 2021

Accepted 5 October 2021

Published 31 October 2021

Online at https:/ / engj.org/

DOI:10.4186/ej.2021.25.10.1 


\section{Introduction}

Plastic has been introduced to the world since the early 20th century. Its production has outshined other man-made materials and is used as an indicator for the development level $[1,2]$. Unfortunately, most of plastics is non-biodegradable and it gradually shrinks into tiny pieces called microplastics, posing a great threat to the ecosystem and food chain [3]. Plastic waste mainly ends up in landfills while less than $10 \%$ enters recycling processes [1]. Plastic pollution has thus become a ubiquitous environmental issue and has gained significant attention in recent years [2]. In 2018, Thailand generated solid waste around 27.9 million tons and 2 million tons of them were plastic waste, including PET bottles, glasses, boxes, plastic bags and bottle caps. However, only a quarter of these plastic wastes, mostly PET bottles, can be recycled [4]. Thailand has been ranked as one of the biggest polluters causing marine plastic pollution. Therefore, the government has launched the 2018-2030 Waste Management Roadmap containing two major objectives. The first one is to reduce, ban, and substitute specific types of plastic. Microbeads, cap seal, and oxo-plastics have been banned since 2019. Plastic straw, styrofoam container, thin plastic bag, and singleused plastic cup are all planned to be phased out in 2022. The second objective is $100 \%$ reuse of all-type plastics by 2027 through the implementation of three measures: reducing waste generation at source, reducing waste through consumption chain, and managing plastic waste after consumption [5]. Following this roadmap, the singleuse plastic bag baning campaign in shopping malls, convenience stores, and supermarkets has been launched since the beginning of 2020, which was supposed to reduce plastic consumption and plastic waste generation.

However, the arrival of COVID-19 pandemic in Thailand in early 2020 impacts the consumer behavior on plastic waste generation. The skyrocketed rise in delivery businesses brought an increase of plastic waste up to $15 \%$, in Bangkok [6]. Thailand Environment Institute Foundation (TEI) also estimated the 60\% increase of plastic waste during COVID-19 in 2020. Furthermore, the growth of food delivery businesses in Thailand expanded more than $200 \%$ during the work from home period, increasing the amount of plastic food packaging to 550 million pieces per year [7]. Many attempts from various organizations have been initiated to encounter this situation. Among them, "Send Plastic Home Project" has been launched under the cooperation of Ministry of Natural Resources and Environment and Thailand Responsible Business Network (TRBN) along with public and private sectors. This project focuses on encouraging people to separate their household plastic wastes by providing knowledge on the waste separation and plastic waste drop-off facilities in public areas. Besides improving waste management, used plastic is expected to be returned to the recycling or recovery processes, which is one among basic concepts of circular economy in attempt to promote responsible consumption, sustainable markets, and protection of natural resources [8-10]. Ten plastic drop- off points have been placed in different locations on Sukhumvit Road to receive clean and dry plastics, either hard or stretchy. The concept of drop-off points conforms the study result indicating that the supply of recycling services has significant effects on household recycling. Among various methods, installing drop-off centers has been considered most effective due to its low cost and less time-consuming [11, 12]. To date, few researchers have pointed out that bin design [10] and public relation [13] play a key role in waste separation behaviors. Additionally, the information availability, public engagement, sorting instruction, and public perception are also crucial parameters $[14,15]$.

The effective drop-off points can be achieved by understanding people's perception and behaviors on waste separation $[14,15]$. Comparing to others [16], the Theory of Planned Behaviour (TPB) is considered a potential tool helping to understand people's intention through various factors, e.g., attitude, subjective norm, and perceived behavioral control [17], which are all elements leading to waste separation behaviors. In china, they use the TPB model with additional analysis methods to establish an environmental regulation enhancing the responsibility of residents, personal involvement, and knowledge for household waste soring [18].

Hence, the objective of this study is to construct the evaluation method for a plastic drop-off point in terms of the Productivity Index (PI). Other relevant factors affecting drop-off point's performance were also analyzed. Moreover, the behavioral study was conducted using the TPB method in order to investigate people's behavior on waste seperation and involvement in drop-off facility. The results obtained from this work can be applied for the improvement of existing drop-off points and for the planning of further drop-off point installation. Effective plastic drop-off points together with people's environmental behaviors would definitely promote waste recycling and circular economy in Thailand.

\section{Materials and Methods}

\subsection{Data Analysis}

Plastic drop-off points studied in this work are listed in Table 1 including ten drop-off points in the Send Plastic Home Project and seven drop-off points of the WON Project. Note that the WON Project has been operated for years before the Send Plastic Home Project was initiated. Stretchy plastic collected from both projects was transported to the recycling facility operated by TPBI PCL. However, this work only considered the amount of stretchy plastic obtained from the Send Plastic Home Project while the information from WON Project was employed for factor analysis.

\subsubsection{Quantitative data}

The collected stretchy plastic from each drop-off point, both recyclable and non-recyclable, was weighed to 
determine its quantity. Moreover, we gathered important data tending to pose the effect on drop-off point performance. Those data included number of parking lots; parking prices; distances from a nearby BTS/MRT station; number of restaurants; number of daily visitors; public advertisement/campaign; bin design; operating hours; opening time; closing time; and the usable area.

Table 1. Drop-off points of Send Plastic Home and WON Projects.

\begin{tabular}{|c|c|c|}
\hline Type & $\begin{array}{c}\text { Send Plastic } \\
\text { Home Project }\end{array}$ & WON Project \\
\hline Building & 1) Singha Complex & $\begin{array}{l}\text { 1) NIAH } \\
\text { 2) Arch KU } \\
\text { 3) Enco A }\end{array}$ \\
\hline $\begin{array}{l}\text { Community } \\
\text { mall }\end{array}$ & $\begin{array}{l}\text { 1) Bambini Villa } \\
\text { 2) A Square } \\
\text { 3) The Commons } \\
\text { Thonglor }\end{array}$ & \\
\hline Mall & $\begin{array}{l}\text { 1) Tesco Lotus } \\
\text { Sukhumvit } 50 \\
\text { 2) EmQuartier } \\
\text { 3) Emporium }\end{array}$ & \\
\hline Restaurant & $\begin{array}{l}\text { 1) Broccoli } \\
\text { Revolution } \\
\text { 2) Veggiology }\end{array}$ & $\begin{array}{l}\text { 1) Midsummer } \\
\text { 2) Refill Station } \\
\text { 3) The Gallery } \\
\text { Sushi } \\
\text { 4) Hwankrob }\end{array}$ \\
\hline Supermarket & $\begin{array}{l}\text { 1) CP Freshmart } \\
\text { (Sukhumvit 39) }\end{array}$ & \\
\hline
\end{tabular}

Factor analysis of mixed data (FAMD), which is a principal component method used for analyzing a data set containing both quantitative (e.g., usable area, parking lot, parking price) and qualitative variables (e.g., bin design, public relation, related campaign) [19], was applied in this work. FAMD helped reduce the dimensions of different factor types by plotting data of the seventeen drop-off points against the amount of stretchy plastic collected, bin design, and types of location. The analysis was performed by $\mathrm{R}$ version 4.0.2 [20] with FactoMineR package [21].

\subsubsection{Qualitative data}

The qualitative data (i.e., recycling ratio and cleanliness) of the stretchy plastic collected from each drop-off point were provided by the recycling facility, TPBI PCL. The recycling ratio was calculated from the amount of recyclable plastic to the amount of total plastic collected, representing how much plastic types are disposed of correctly. For the plastic's cleanliness, a rating scale from 0 (dirtiest) to 5 (cleanest) was applied.

\subsubsection{Logistics data}

Stretchy plastic, polypropylene (PP) and polyethylene (PE), was collected weekly from drop-off points in Bangkok to the recycling facility in Nakhon Pathom by 4wheel pickup. The transportation route started from A
Square, Bambini Villa, Tesco Lotus Sukhumvit 50, Emporium, EmQuartier, Veggiology, Broccoli Revolution, The Commons Thonglor, CP Freshmart Sukhumvit 39 to Singha Complex, respectively. The logistics cost (L) per round consists of fixed and variable costs as expressed in Eq. (1) where the route distance (D) can be calculated from Eq. (2).

$$
\begin{aligned}
& \text { Logistics cost }(L)=\overbrace{(D \times F)+T}^{\text {Fixed costs }}+\overbrace{V+W}^{\text {Variable costs }} \\
& \text { Route distance }(D)=\sum_{i=n} D_{1}+D_{2}+\ldots+D_{\mathrm{n}}
\end{aligned}
$$

$D=$ Route distance $(\mathrm{km})$ as a round-trip from the recycling facility through all drop-off points in the transportation route

$F=$ Fuel cost $(B a h t / \mathrm{km})$ estimated from fuel price (Baht/liter) and average fuel consumption rate (liter $/ \mathrm{km}$ ) of the vehicle

$T=$ Toll fee (Baht)

$V=$ Rental vehicle cost (Baht)

$W=$ Driver wage (Baht)

\subsubsection{Productivity Index}

We evaluated the performance of each drop-off point through the Productivity Index (PI) calculated from Eq. (3). Logistics cost, quantity, quality, and value of the plastic collected were required for the evaluation. These data were recorded every 2 weeks during the studied period, and their average values were used for the calculation.

$$
\text { Productivity Index }=\frac{M_{\mathrm{r}}}{\mathrm{C}} \times \frac{R \times M_{p} \times P}{L}
$$

$M_{r}=$ Mass of the total collected plastic waste per trip (kg)

$C=$ Maximum capacity of the vehicle $(\mathrm{kg})$

$\mathrm{R}=$ Recycling ratio

$P=$ Plastic waste price (Baht $/ \mathrm{kg})$

$L=$ Logistics cost (Baht)

$M_{p}=$ Plastic mass collected from each drop-off point ( $\left.\mathrm{kg}\right)$

\subsection{Theory of Planned Behavior}

\subsubsection{Research model}

In this work, we applied the Theory of Planned Behavior (TPB) model to study people behaviors on plastic waste separation. TPB assumes that our behaviors are directly influenced by the intention arising from three independent variables, i.e., attitude toward the behavior, subjective norm, and perceived behavioral control. The 'attitude toward the behavior' refers to the degree at which a person has a favorable or unfavorable appraisal of the behavior in question. The 'subjective norm' is a social factor relevant to the perceived social pressure whether to perform the behavior. Lastly, the 'perceived behavioral control' indicates the perception of ease or difficulty to 


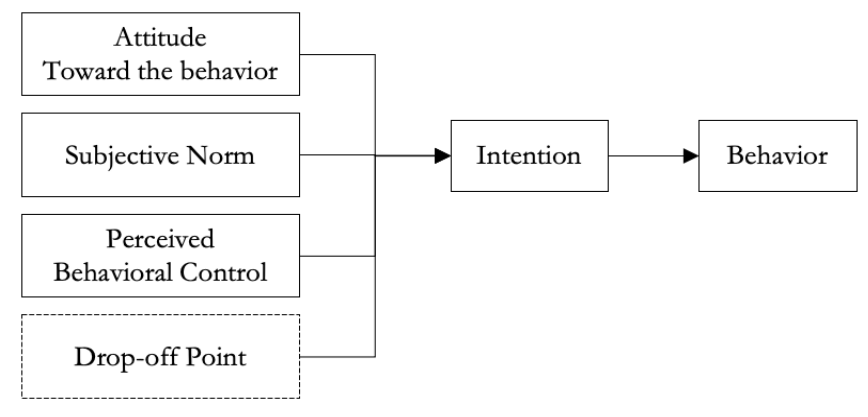

Fig. 1. The extended Theory of Planned Behavior adapted from Stoeva and Alriksson [9].

perform the behavior. This variable is assumed to reflect past experiences as well as anticipated impediments [22]. According to the previous research [9, 23, 24], recycling facilities can strengthen both intention and behavior on waste recycling. Here, a drop-off point was considered a kind of recycling facilities, which was included in the model denoted as the extended TPB (Fig. 1).

\subsubsection{Study approach}

We applied the extended TPB model in the questionnaire survey performed both on-site and online platforms. The questionnaires were prepared in two languages (Thai and English), with the list of variables and questions shown in Table 2. The respondents were asked to read the statements and then indicate the extent at which they agreed or disagreed with the statements using a 5-point Likert-scale ranging from strongly disagree to strongly agree choices.

All calculations were conducted using the SPSS for Windows, version 22. We calculated the Cronbach's alpha coefficient for each variable to ensure the scale reliability of the result on multi-item questions. This coefficient is widely used for assessing Likert-type scales when model components are latent variables measured indirectly through each item [25]. The Structural Equation Modelling (SEM) was used to setup a framework for analyzing the correlation of multiple variables affecting plastic waste separation behavior under the extended TPB model of study [30].

\section{Results and Discussion}

\subsection{Drop-off Point Productivity}

\subsubsection{Drop-off point performance}

During the studied period, the stretchy plastic of 420 kilograms was collected by Send Plastic Home project. As presented in Fig. 2, the amount of collected plastic after 60 days was found highest in EmQuartier $(104.52 \mathrm{~kg}$ ) followed by Tesco Lotus Sukhumvit $50(99.49 \mathrm{~kg})$ and The Commons $(47.68 \mathrm{~kg})$.

Besides the quantity, the plastic's cleanliness is another factor affecting plastic recycling opportunities. The plastic wastes collected from all drop-off points had relatively high cleanliness level of 4 to 5 , which was favorable to the recycling facility. However, during the first week of investigation, a considerable amount of plastic waste collected from Tesco Lotus Sukhumvit 50 held the cleanliness level of only 2 , meaning that the plastic waste was still commingled and difficult to be recycled. We improved this situation by conducting the public relation (PR) campaign relating to plastic waste separation and then observed that the plastic's cleanliness was enhanced to level 4 within two weeks after the PR. This result indicates the importance of PR on people's awareness and behavioral changes in waste separation.

Table 2. Variables from the extended Theory of Planned Behavior including their items applied in the questionnaire.

\begin{tabular}{|c|c|c|}
\hline Variable & Question & Source \\
\hline \multicolumn{3}{|l|}{ Attitude } \\
\hline AT1 & Waste separation is important and necessary & Own wording \\
\hline AT2 & Plastic waste separation can promote resource recycling and utilization & " \\
\hline \multicolumn{3}{|c|}{ Subjective norm } \\
\hline SN1 & People around me think that plastic waste separation is useful & $"$ \\
\hline SN2 & People around me are one among reasons why I want to separate plastic waste & $"$ \\
\hline \multicolumn{3}{|c|}{ Perceived behavioral control } \\
\hline PBC1 & I know how to correctly separate plastic waste & [26] \\
\hline PBC2 & Plastic waste separation can be easily conducted & [26] \\
\hline \multicolumn{3}{|c|}{ Drop-off point } \\
\hline DP1 & Because there are plastic waste drop-off points, I started to separate plastic waste & Own wording \\
\hline \multicolumn{3}{|c|}{ Intention } \\
\hline IN1 & I intend to separate plastic waste as much as possible within a month & {$[27]$} \\
\hline \multicolumn{3}{|c|}{ Behavior } \\
\hline BE1 & I usually separate plastic waste & [28] \\
\hline BE2 & I always take separated plastic waste to recycle bin & [29] \\
\hline
\end{tabular}




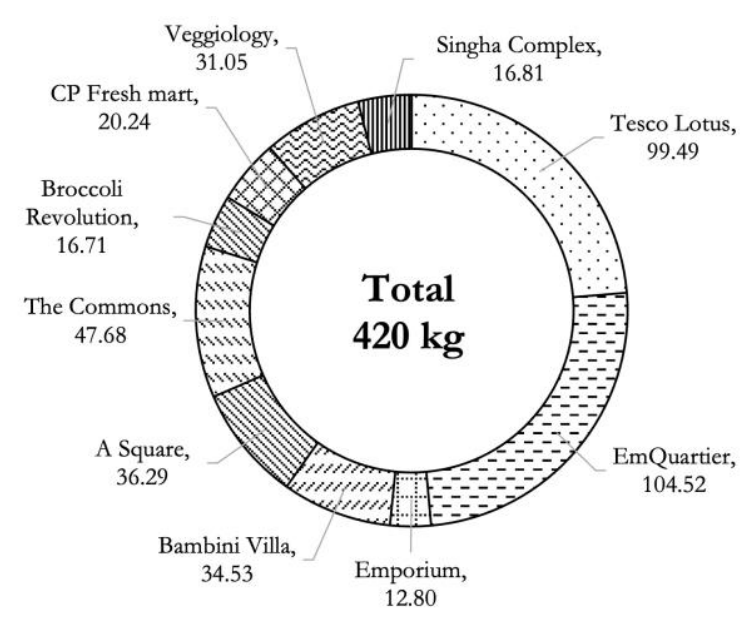

Fig. 2. Total weight of the collected stretchy plastic waste $(\mathrm{kg})$ from Send Plastic Home project operated for 60 days $\left(12^{\text {th }}\right.$ May $-11^{\text {th }}$ July 2020$)$.

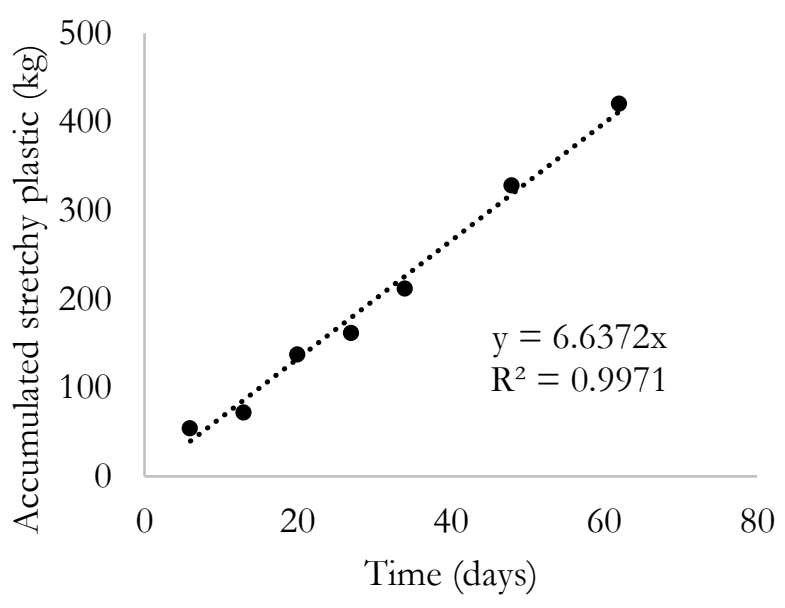

Fig. 3. The accumulated stretchy plastic from Send Plastic Home project during 60 days of the studied period.

\subsubsection{Logistics data}

Currently, the pickup truck with 300-kg capacity was used for collecting the stretchy plastic from all drop-off points to the recycling facility, contributing to the logistics cost of 1,350 baht (210 baht and 1,140 baht for fixed and variable costs, respectively). This $300-\mathrm{kg}$ capacity of the vehicle must be fully utilized to maximize the transportation's cost-effectiveness. Therefore, we plotted data between the accumulated plastic mass versus the collection periods as displayed in Fig. 3. The result exhibited a linear relationship $\left(\mathrm{R}^{2}=0.9971\right)$, which can predict the proper time to collect the plastic waste from drop-off points as Eq. (4).

$$
\mathrm{y}=6.6372 \mathrm{x}
$$

$\mathrm{y}=$ Accumulated stretchy plastic $(\mathrm{kg})$ $\mathrm{x}=$ Time (days)

For this case, instead of weekly collection, the plastic waste should be stored at the drop-off point up to 46 days to achieve the maximum $300-\mathrm{kg}$ capacity. This information is useful for designing the transportation plan as well as for preparing the storage at each drop-off point in order to minimize the logistics cost, which is the largest concern in the circular plastic management.

\subsubsection{Productivity Index (PI)}

As shown in Fig. 4, PI can be divided into two groups: (1) high PI $(>0.005)$ for Tesco Lotus Sukhumvit 50 and EmQuartier and (2) low PI $(<0.002)$ for the remaining locations. For the high PI group, it can be noticed that EmQuartier had a greater mean PI than that of Tesco Lotus, from which more plastic waste could be collected. This result suggests that the amount of plastic waste collected is not the only factor reflecting on the productivity of drop-off points. It was also interesting that the outlier PI found in A Square, The Commons, Broccoli Revolution, CP Freshmart, and Veggiology exhibited the potential of these locations to increase their PI.

Studying PI is helpful for evaluating the performance and optimizing the location of drop-off points. To improve the PI, several approaches can be conducted; for example, displacing the drop-off point or gathering plastic wastes from nearby points to a single place in order to facilitate the transportation and thus reducing the logistics cost. It was clear that the location of a drop-off point plays a crucial role on its productivity. People are likely to use a drop-off point more frequently if the travel distance from their home to the site is short [31]. Nevertheless, the location might not be the only factor affecting the productivity. We thus incorporated other relevant factors into consideration. In this work, the factor analysis of mixed data (FAMD) was performed to identify key variables governing the drop-off point's productivity. The results are explained in the following part.

\subsubsection{FAMD analysis}

FAMD was applied to determine the influence of ten variables on the drop-off point performance. The variables of study were compiled from literatures $[10,13$, 31] and field-survey observation, including (1) bin design, (2) opening and closing time of the location, (3) space of the location, (4) distance from a BTS or an MRT station, (5) number of restaurants, (6) number of parking lot, (7) parking price, (8) operating hours of the location, (9) traffic level of the location, and (10) PR and campaign related to the plastic waste collection.

In this study, drop-off point locations under the Send Plastic Home project could be divided into three groups according to the traffic in the area, which reflected on a number of people accessible to the drop-off point. The first group was drop-off points with heavy traffic, including EmQuartier, Emporium, and Tesco Lotus 
Sukhumvit 50. The second group with moderate traffic comprised A Square, CP Freshmart, The Commons, Singha Complex, and Bambini Villa. Lastly, Veggiology and Broccoli Revolution were classified as a light-traffic group.

Figure 5 presents the analytical data obtained from FAMD. By projecting all variables into two-dimensional plots, the first and the second component explained $28.7 \%$ and $16 \%$ of the variation, respectively. The total of $44.7 \%$ data analysis might not be able to describe the individual drop-off point, but it could suggest the potential factors influencing the overall drop-off point performance. The first component was most impacted by bin design, parking lots, and traffic levels, respectively. Meanwhile, the second component was most affected by bin design, closing time, and operating hours. It is obvious that bin design had the largest impact on the amount of stretchy plastic obtained from each drop-off point. Bin appearance is the first thing people notice and can differentiate the drop-off point from general trash bins. Bins with nice or unique design can attract people attention and motivate them towards waste separation. For example, a drop-off point at Tesco Lotus Sukhumvit 50 offered a step-on bin installed with sound motion sensor. This design could obviously distinguish the plastic drop-off bin from others and thus played a key role in improving the quality of plastic waste collected.

Parking lots, closing time, and operating hours indicate the capability of people to access drop-off points anytime they are available. The largest portions of plastic waste were collected from EmQuartier and Tesco Lotus Sukhumvit 50 since these locations have more parking lots provided. Moreover, their long operating hours (i.e., Gam to $12 \mathrm{am})$ allows people to access the drop-off point either in the early morning or in the late night. In terms of the traffic level, large hypermarket and shopping malls like Tesco Lotus Sukhumvit 50, EmQuartier, and Emporium were categorized as the heavy traffic area, and large amounts of the stretchy plastic waste were expected. However, Emporium received a small amount of the stretchy plastic, which accounted for only 3\% of the total. Emporium is located opposite to the EmQuartier, and both of them are connected with the BTS station. Since Emporium is considered a luxury shopping mall, most people would rather go to EmQuartier, which is more compatible to their varied lifestyles. This could be a reason behind the small amount of plastic collected from the drop-off point at Emporium.

The medium and small amounts of collected plastic were mostly found in community malls and restaurants, respectively. This is exceptional for Veggiology, which is a restaurant with the medium amount of plastic waste collected $(28.85 \mathrm{~kg})$. Besides the drop-off point from 'Send Plastic Home' project, Veggiology also provides another drop-off point from 'WON' inside the shop. Therefore, people are familiar to drop the stretchy plastic here combining with the discarded plastic from the shop itself. Enco A and Singha Complex are a large working place, which is supposed to have the moderate traffic. Surprisingly, these two locations got the small amount of plastic collected. Apart from building staff and employees, difficulties for people to access these locations might be responsible for this result.

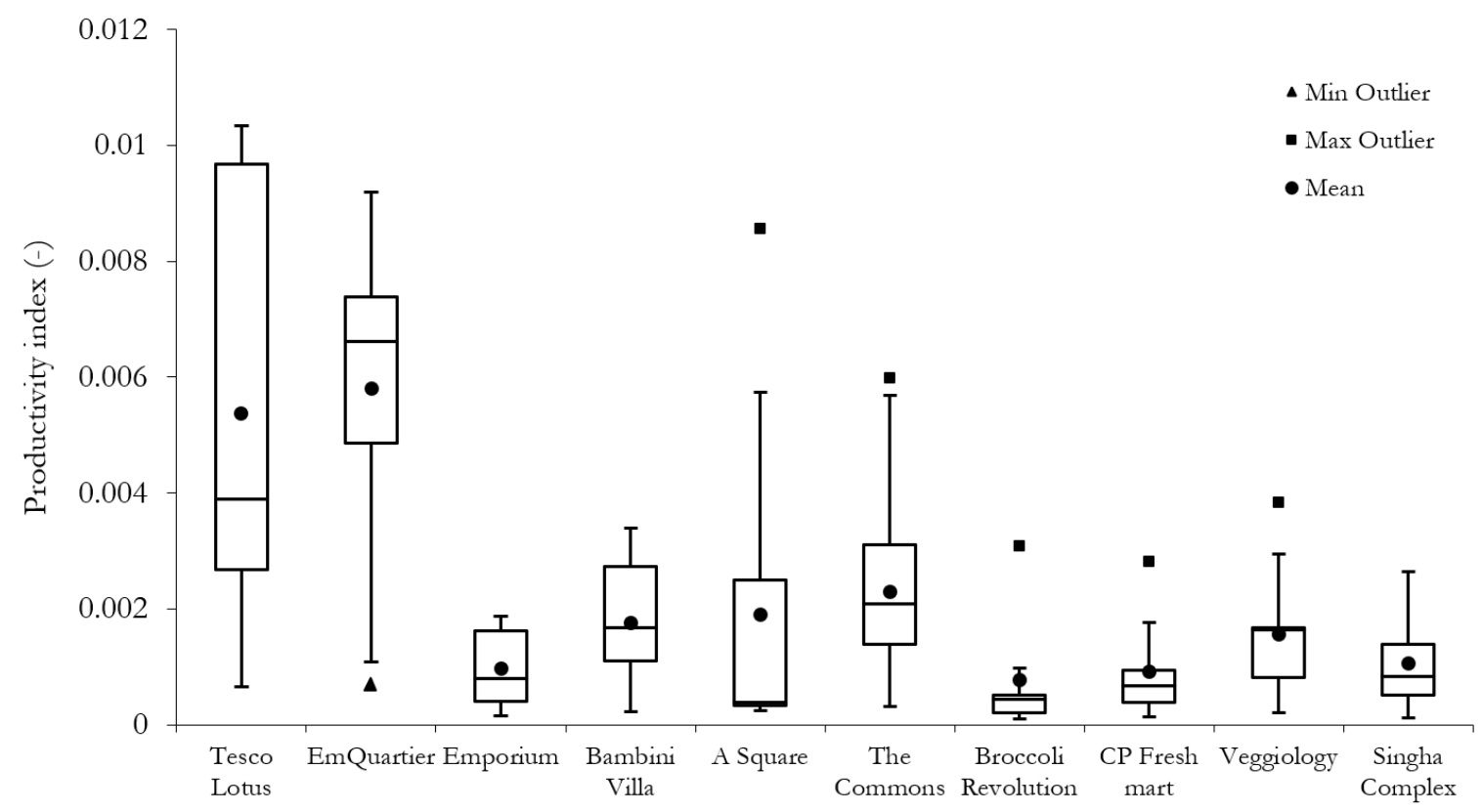

Fig. 4. Boxplots of Productivity Index of each drop-off point. 


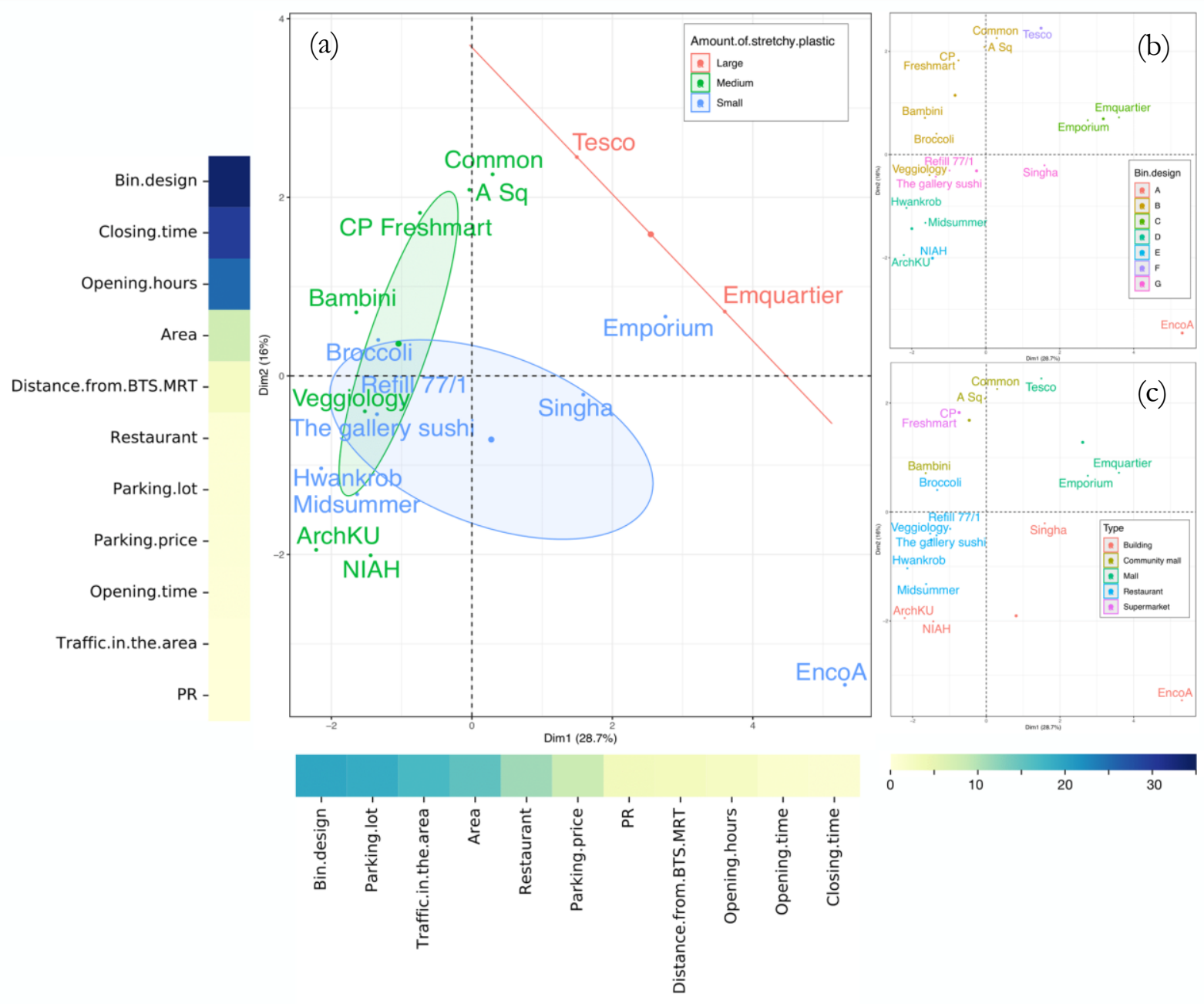

Fig. 5. The representation of individuals from FAMD labeled by (a) an amount of stretchy plastic, (b) bin design, and (c) types of location. The contributed proportion of each factor to the component was presented by the heatmap. The stretchy plastic collected from each drop-off point was classified as a small $(<20 \mathrm{~kg})$, medium $(20-70 \mathrm{~kg})$, and large $(>70$ $\mathrm{kg}$ ) amount. The bin design included A: acrylic open-top bin, B: white push-in cover bin, C: step-on bin, D: yellow push-in cover bin with covered cardboard, E: gray lid-opening bin, F: step-on bin equipped with sound, and G: no bin.

\subsection{Extend Theory of Planned Behavior (TPB)}

Considering Eq. (3), the PI of each drop-off point can be improved by increasing the recycling ratio and weight of the collected plastic. These two parameters are relevant to people's perception and understanding on plastic waste separation as well as a number of people participated in the project. Therefore, well-communicating the project's target and providing necessary knowledge on plastic waste separation are necessary to achieve the effective plastic waste collection at drop-off points. According to previous research, people tended to use drop-off points more often when they felt that recycling is convenient and they are familiar with the recycling infrastructure [23]. A belief that recycling is good for the environment [11] and social pressure [32] are also the significant motivations for household recycling behavior. In this work, we applied TPB to study people's intention and behavior on waste separation. The results obtained from TPB could lead to an intervention promoting efficient waste separation and recycling.

The questionnaires were completed by 484 respondents submitted via online platforms. Sociodemographic data of the respondents are displayed in Table 3. Majority of the respondents was female (84.1\%), and two-third of the respondents $(66.7 \%)$ was in the age of $31-50$ years old. It was found that $67.6 \%$ of the respondents were aware of this project from Facebook and they would like the project to expand the communication through other channels, particularly the mass media such as television.

Once the questionnaire's responses were summarized, we then tested the validity of the measurement model. The confirmatory factor analysis (CFA) was applied to examine the model fitting level through several parameters, including CFI (comparative fit index), GFI (goodness of fit), AGFI (adjusted goodness of fit), and RMSEA (rootmean-square error of approximation). CFA refers to a technique for assessing how well the observed items 
represent the model by considering the recommended acceptance levels [30]. The criteria to evaluate the model fit are provided in Table 4 . The result showed that all model fitting parameters agreed with the recommended acceptance levels.

Table 3. Socio-demographic data of the respondents.

\begin{tabular}{lcc}
\hline Parameter & Number & Percentage \\
\hline Age: & & \\
$15-30$ & 86 & 17.8 \\
$31-50$ & 323 & 66.7 \\
Over 51 & 75 & 15.5 \\
Sex: & & \\
Male & 74 & 15.3 \\
Female & 407 & 84.1 \\
Other & 3 & 0.6 \\
\hline
\end{tabular}

Table 4. Confirmatory factor analysis of the measurement model studied in this work

\begin{tabular}{|c|c|c|c|c|}
\hline \multirow[b]{2}{*}{$\begin{array}{l}\text { Model } \\
\text { Fit } \\
\text { Criteria }\end{array}$} & \multicolumn{4}{|c|}{ TPB model } \\
\hline & $\begin{array}{c}15-30 \\
\text { years } \\
\text { old }\end{array}$ & $\begin{array}{c}31-50 \\
\text { years } \\
\text { old }\end{array}$ & $\begin{array}{c}>51 \\
\text { years } \\
\text { old }\end{array}$ & $\begin{array}{c}\text { Recommended } \\
\text { acceptance } \\
\text { levels }\end{array}$ \\
\hline CFI & 0.91 & 0.94 & 0.99 & $>0.9$ \\
\hline GFI & 0.92 & 0.96 & 0.94 & $>0.9$ \\
\hline AGFI & 0.84 & 0.93 & 0.88 & $>0.8$ \\
\hline RMSEA & 0.08 & 0.07 & 0.02 & $<0.08$ \\
\hline
\end{tabular}

Cronbach's alpha reliability coefficient normally ranges between 0 and 1. The closer Cronbach's alpha coefficient is to 1 , the greater internal consistency among the items in the scale. Table 5 presents the Cronbach's alpha coefficient for four parameters studied via TPB. Drop-off point and intention were not considered since they belonged to a single-item question. The reliability was found highest for attitude, behavior, subjective norm, and perceived behavioral control, respectively. All variables with the Cronbach's alpha values above 0.60 showed their acceptable internal consistency [33, 34]. Whereas, the perceived behavioral control with Cronbach's alpha coefficient of 0.50 exhibited the moderate reliability [35].

Table 5. Cronbach's alpha coefficient for each variable.

\begin{tabular}{lc}
\hline Variables & Cronbach's alpha \\
\hline Attitude & 0.90 \\
Subjective norm & 0.67 \\
Perceived behavioral control & 0.50 \\
Behavior & 0.68 \\
\hline
\end{tabular}

As shown in Fig. 6a, the strongest predictor of intention in the sample aging 15-30 years old was perceived behavior control, drop-off point, and attitude, respectively. The result corresponds to the previous research reporting that attitude, perceived behavior control, and satisfaction with local facilities were a significant predictor influencing waste separation behavior for university students (age 18-24 years old) [9]. For the respondents with 31-50 years old, their intention was most influenced by drop-off point, attitude, and perceived behavioral control, respectively (Fig. 6b). Meanwhile, attitude was the predictor most affected the intention of respondents over 51 years old, followed by perceived behavioral control, drop-off point, and subjective norm (Fig. 6c).
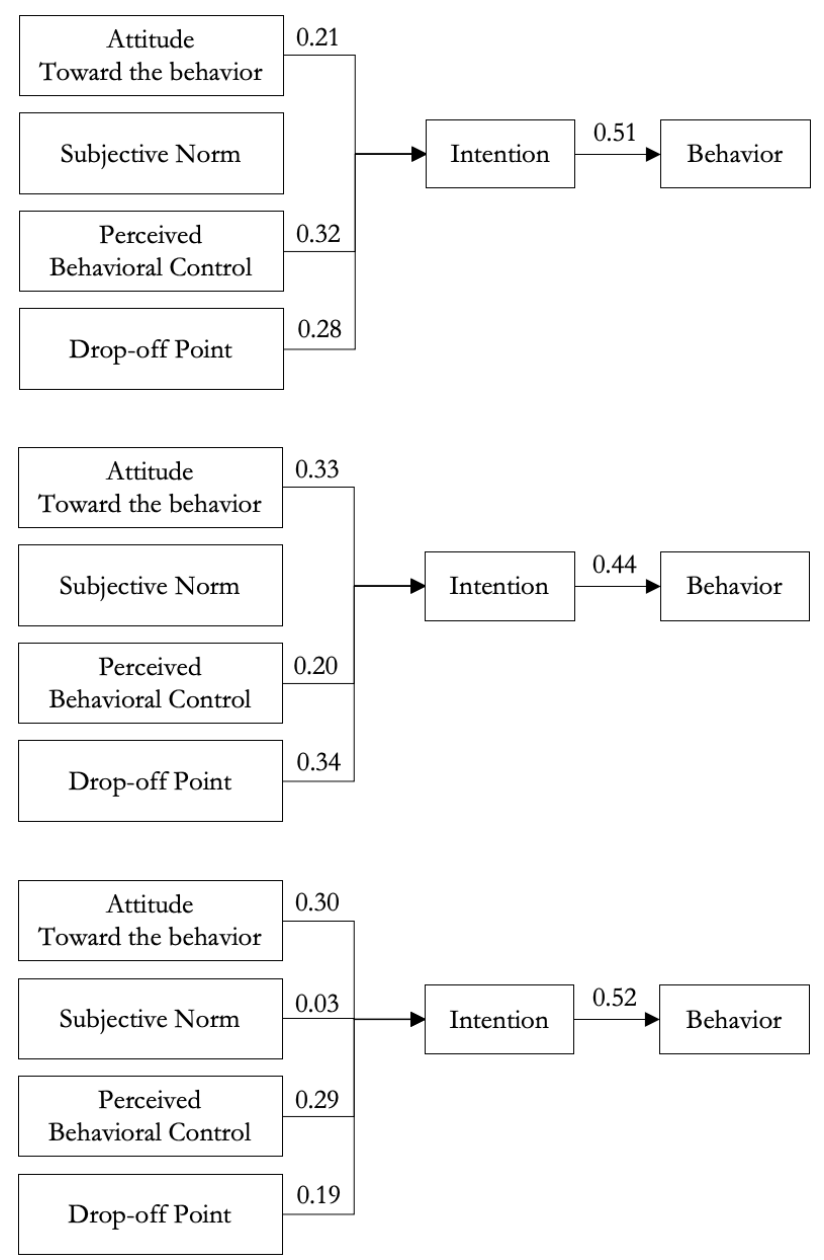

Fig. 6. Structural Equation Modelling (SEM) for evaluating factors affecting plastic waste separation behavior: (a) 15-30 years old, (b) 31-50 years old, and (c) over 51 years old.

It is obvious that attitude became a more significant factor as people get aged. Environmental awareness is one key driving force stimulating the environmental attitude [28], which further brings their intention toward plastic waste separation. Therefore, communicating with people particularly young generation on current environmental impacts such as plastic waste pollution, landfill emissions, and depletion of natural resources could help improve plastic waste separation behaviors. Additionally, relevant marketing and campaigns should emphasize people on waste separation at source/home and offer the valuable outcomes after their participation [29]. The perceived behavioral control was most significant to people of 15-30 
and over 51 years old. Their decision whether to separate plastic wastes may depend upon how fast and how easy to separate them. To promote their separation behavior, providing suggestions or knowledge on the correct plastic waste separation and designing products easy to separate could be helpful. For the subjective norm, only the respondents over 51 years old responded to this factor but in a very low degree. The standardized coefficients ranging from 0.4-0.5 were observed between intention and behavior for all ages. This result implies that there would be other factors influencing plastic waste separation behavior and they were not included in this research model, e.g., socio-economic factors, environmental assessment, awareness towards environmental problems, attribution of responsibility, habit, new environmental paradigm, self-transcendence value and self-enhancement value [36-37]. In addition to social factors, a physical tool such as drop-off points was also of importance, especially for people aged 31-50 years old. Installation of effective drop-off points (considering bin design, location, convenience, etc.), not only improves plastic waste separation behavior, but increase the PI of plastic recycling facilities.

\section{Conclusion}

Drop-off points are a low-cost and less timeconsuming implement for plastic waste recycling services. In this work, we develop the Productivity Index (PI) for plastic drop-off points, considering mass of plastic collected, recycling ratio, logistics data (i.e., capacity and cost), as well as plastic waste prices. PI can be applied as an indicator to evaluate how effective the current drop-off point is and to help designing further installation of dropoff point facilities.

We observed that plastic waste separation behavior is of most concern. Proper separation of plastic waste in terms of type and cleanliness can significantly improve the drop-off point's PI and enable the successful plastic waste recycling system. People's intention towards plastic waste separation attributes to not only their environmental attitude and perceived behavioral control but drop-off point facility, especially those of 31-50 years old. To improve the quality and quantity of plastic waste collected, information regarding plastic waste's impacts and its value after separation should be more communicated. Moreover, bins and locations of drop-off points should be carefully optimized focusing on the attractiveness and convenience for people. These findings support plastic waste recycling programs as well as the circular economy in Thailand. Additionally, the intervention inducing people's behavioral changes could help to design and improve the policies relating to waste separation and recycling.

\section{Acknowledgement}

This research project is supported by Second Century Fund (C2F), Chulalongkorn University and the Research Program on Development of Technology and
Management Guideline for Green Community granted by the Center of Excellence on Hazardous Substance Management (HSM). The support from Ratchadapisek Somphot Fund for Postdoctoral Fellowship, Chulalongkorn University is also acknowledged. Finally, we thank the Thailand Responsible Business Network (TRBN) and TPBI Public Co., Ltd. for their data supported in this research.

\section{References}

[1] R. Geyer, J. R. Jambeck, and K. V. Law, "Production, use, and fate of all plastics ever made," Science Advances, vol. 3, pp. 1-5, Jul. 2017.

[2] G. C. Brighty, D. Jones, and J. Ruxton, High-Level Science Review for 'A Plastic Oceans' Film. 2017. [Online]. Available: https://plasticoceans.org/wpcontent/uploads/2017/01/Plastic-Oceans-High-

Level-Science-Summary-Version-4.pdf. Accessed: 3 August 2020.

[3] H. S. Auta, C. U. Emenike, and S. H. Fauziah, "Distribution and importance of microplastics in the marine environment: A review of the sources, fate, effects, and potential solutions," Environment International, vol. 102, pp. 165-176, May 2017.

[4] Pollution Control Department, "Thailand state of pollution report 2018,” 2018. Accessed: Aug. 7, 2020. [Online].

Available: http://www.pcd.go.th/file/AW-PollutionReport2018.pdf

[5] Pollution Control Department, "Roadmap of plastic wastes management 2018-2030,” 2018. Accessed: Aug. $7, \quad 2020$. [Online]. Available: http://www.pcd.go.th/Info_serv/File/

Plastic\%20Roadmap\%20Poster.jpg

[6] Bangkokbiznews. "Ministry of Natural Resources and Environment suggests that plastic wastes from a delivery process increase 15\%." Bangkokbiznews.com.

https://www.bangkokbiznews.com/news/detail/ 8 77514 (accessed: Aug. 3, 2020).

[7] Thaipost. "Plastic waste problem following the new COVID-19." Thaipost.net. Available: https://www.thaipost.net/main/detail/89342 (accessed: Feb. 19, 2021).

[8] J. Singh and I. Ordonez, "Resource recovery from post-consumer waste: Important lessons for the upcoming circular economy," Journal of Cleaner Production, vol. 134, pp. 342-353, Oct. 2016.

[9] K. Stoeva, and S. Alriksson, "Influence of recycling programmes on waste separation behaviour," $W$ aste Management, vol. 68, pp. 732-741, Oct. 2017.

[10] I. Zelenika, T. Moreau, and J. Zhao, "Toward zero waste events: Reducing contamination in waste streams with volunteer assistance," Waste Management, vol. 76, pp. 39-45, Jun. 2018.

[11] B. Halvorsen, "Effects of norms and policy incentives on household recycling: An international 
comparison," Resources, Conservation and Recycling, vol. 67, pp. 18-26, Jun. 2012.

[12] J. M. Saphores, H. Nixon, O. A. Ogunseitan, and A. A. Shapiro, "Household willingness to recycle electronic waste: an application to California," Environ. Behav, vol. 38, no. 2, pp. 183-208, Mar. 2006.

[13] M. Robertson, Communicating Sustainability, $1^{\text {st }}$ ed. Abingdon, England: Routledge, 2018.

[14] K. Rousta, K. Bolton, M. Lundin, and L. Dahlén, "Quantitative assessment of distance to collection point and improved sorting information on source separation of household waste," Waste Management, vol. 40, pp. 22-30, Jun. 2015.

[15] M. R. Puigvert, S. Ayuso, A. Bala, and P. Fullana-IPalmer, "What factors determine attitudes towards the implementation of a packaging deposit and refund system? A qualitative study of the perception of Spanish consumers," Journal of Environmental Management, vol. 270, Jun. 2020.

[16] S. Phuphisith, K. Kurisu, and K. Hanaki, "A comparison of the practices and influential factors of pro-environmental behaviors in three Asian megacities: Bangkok, Tokyo, and Seoul," Journal of Cleaner Production, vol. 253, Apr. 2020.

[17] W. Strydom, "Applying the theory of planned behavior to recycling behavior in South Africa," Recycling, vol. 3, no. 3, pp. 43, Sep. 2018.

[18] Y. Wang, X. Long, L. Li, Q. Wang, X. Ding, and S. Cai, "Extending theory of planned behavior in household waste sorting in China: The moderating effect of knowledge, personal involvement, and moral responsibility," Environment, Development and Sustainability, vol. 23, no. 5, pp. 7230-7250, 2020, doi:10.1007/s10668-020-00913-9.

[19] J. Pagès, "Analyse Factorielle de Donnees Mixtes," Revue Statistique Appliquee, vol. 4, pp. 93-111, 2004,

[20] R Core Team, R: A Language and Environment for Statistical Computing, Vienna, Austria: R Foundation for Statistical Computing, 2020. [Online]. Available: https://www.R-project.org. Accessed: Aug. 3, 2020.

[21] S. Lê, J. Josse, and F. Husson, "FactoMineR: A package for multivariate analysis," Journal of Statistical Software, vol. 25, no. 1, pp. 1-18, 2008, doi: $10.18637 /$ jss.v025.i01.

[22] I. Ajzen, "The theory of planned behavior," Organizational Behavior and Human Decision Processes, vol. 50, pp. 179-212, Dec. 1991.

[23] S. F. Sidiquea, F. Lupib, and S. V. Joshi, "The effects of behavior and attitudes on drop-off recycling activities," Resources, Conservation and Recycling, vol. 54, pp. 163-170, Aug. 2009.

[24] M. F. Chen and P. J. Tung, "The moderating effect of perceived lack of facilities on consumers' recycling intentions," Environment and Behavior, vol. 42, no. 6, pp. 824-844, 2010.

[25] J. A. Gliem and R. R. Gliem, "Calculating, interpreting, and reporting Cronbach's alpha reliability coefficient for likert-type scales," in 2003 Midwest Research-to-Practice Conference in Adult, Continuing, and Community Education., Columbus, 2003, pp. 82-88.

[26] M. Tonglet, P. S. Phillips, and A. D. Read, "Using the Theory of Planned Behaviour to investigate the determinants of recycling behaviour: A case study from Brixworth, UK," Resources, Conservation and Recycling, vol. 41, pp. 191-214, Jun. 2004.

[27] T. Ioannou, L. Zampetakis, and K. Lasaridi, "Psychological determinants of household recycling intention in the context of the Theory of Planned Behaviour," Fresenius Environmental Buletin, vol. 22, pp. 2035-2041, Jan. 2013.

[28] T. Ramayah, J. Lee, and S. Lim, "Sustaining the environment through recycling: An empirical study," Journal of Environmental Management, vol. 102, pp. 141147, Jul. 2012.

[29] W. Karim Ghani, I. Rusli, D. Biak, and A. Idris, “An application of the theory of planned behaviour to study the influencing factors of participation in source separation of food waste," Waste Management, vol. 33, pp. 1276-1281, May 2013.

[30] A. P. Bortoleto, K. H. Kurisu, and K. Hanaki, "Model development for household waste prevention behaviour," Waste Management, vol. 32, pp. 2195-2207, Dec. 2012.

[31] S. F. Sidique, F. Lupi, and S. V. Joshi, "Estimating the demand for drop-off recycling sites: A random utility travel cost approach," Jornal of Environmental Management, vol. 127, pp. 339-346, May 2013.

[32] T. Ramayah, J. W. C. Lee, and S. Lim, "Sustaining the environment through recycling: An empirical study," Journal of Environmental Management, vol. 102, pp. 141-147, Mar. 2012.

[33] J. F. Hair, W. C. Black, Jr., B. J. Babin, and R. E. Anderson, Multivariate Data Analysis, 7 th ed. Pearson, 2015.

[34] A. Field, Discovering Statistics Using IBM SPSS Statistics, $4^{\text {th }}$ ed. California: SAGE Publishing, 2013.

[35] P. R. Hilton, C. Brownlow, I. McMurray, and B. Cozens, SPSS Explain, 1st ed. Routledge, 2004.

[36] F. Echegaray and F. V. Hansstein, "Assessing the intention-behavior gap in electronic waste recycling: the case of Brazil," Journal of Cleaner Production, vol, 142, pp. 180-189, Jan. 2017.

[37] C. A. Klöckner, "A comprehensive model of the psychology of environmental behaviour-A metaanalysis," Global Environmental Change, vol. 23, pp. 1028-1038, Oct. 2013. 
Pavinee Pongpunpurt, photograph and biography not available at the time of publication.

Natsuda Navamajiti, photograph and biography not available at the time of publication.

Kerkritt Sriroongvikrai, photograph and biography not available at the time of publication.

Muentawan Onnom, photograph and biography not available at the time of publication.

Pat Pinitjitsamut, photograph and biography not available at the time of publication.

Pisut Painmanakul, photograph and biography not available at the time of publication.

Nattawin Chawaloesphonsiya, photograph and biography not available at the time of publication.

Thaksina Poyai, photograph and biography not available at the time of publication. 